\title{
Compact and Lightweight Sabatier Reactor for Carbon Dioxide Reduction
}

\author{
Christian Junaedi ${ }^{1}$, Kyle Hawley ${ }^{2}$, Dennis Walsh ${ }^{3}$ and Subir Roychoudhury ${ }^{4}$ \\ Precision Combustion, Inc., North Haven, CT, 06473 \\ Morgan B. Abney ${ }^{5}$ and Jay L. Perry ${ }^{6}$ \\ NASA George C. Marshall Space Flight Center, Huntsville, AL, 35812
}

\begin{abstract}
The utilization of $\mathrm{CO}_{2}$ to produce life support consumables, such as $\mathrm{O}_{2}$ and $\mathrm{H}_{2} \mathrm{O}$, via the Sabatier reaction is an important aspect of NASA's cabin Atmosphere Revitalization System and In-Situ Resource Utilization architectures for both low-earth orbit and long-term manned space missions. In the current International Space Station (ISS) and other low orbit missions, metabolically-generated $\mathrm{CO}_{2}$ is removed from the cabin air and vented into space, resulting in a net loss of $\mathrm{O}_{2}$. This requires a continuous resupply of $\mathrm{O}_{2}$ via water electrolysis, and thus highlights the need for large water storage capacity. For long-duration space missions, the amount of life support consumables is limited and resupply options are practically nonexistent, thus atmosphere resource management and recycle becomes crucial to significantly reduce necessary $\mathrm{O}_{2}$ and $\mathrm{H}_{2} \mathrm{O}$ storage. Additionally, the potential use of the Martian $\mathrm{CO}_{2}$-rich atmosphere and Lunar regolith to generate life support consumables and propellant fuels is of interest to NASA. Precision Combustion, Inc. (PCI) has developed a compact, lightweight Microlith ${ }^{\circledR}$-based Sabatier $\left(\mathrm{CO}_{2}\right.$ methanation) reactor which demonstrates the capability of achieving high $\mathrm{CO}_{2}$ conversion and near $100 \% \mathrm{CH}_{4}$ selectivity at space velocities of $30,000-60,000 \mathrm{hr}^{-1}$. The combination of the Microlith ${ }^{\circledR}$ substrates and durable, novel catalyst coating permitted efficient Sabatier reactor operation that favors high reactant conversion, high selectivity, and long-term durability. This paper presents the reactor development and performance results at various operating conditions. Additionally, results from 100-hr durability tests and mechanical vibration tests are discussed.
\end{abstract}

\section{Nomenclature}

$\begin{array}{ll}C & =\text { Celcius } \\ d & =\text { diameter } \\ G H S V & =\text { gas hourly space velocity } \\ G S & =\text { gravity (force) } \\ G S A & =\text { geometric surface area } \\ h r & =\text { hour } \\ H z & =\text { hertz } \\ \text { in } & =\text { inch } \\ k J & =\text { kilojoules } \\ L & =\text { length } \\ m & =\text { meter } \\ m l & =\text { milliliter }\end{array}$

${ }^{1}$ Research Engineer, Microlith ${ }^{\circledR}$ Products, 410 Sackett Point Rd., North Haven, CT 06473.

${ }^{2}$ Development Engineer, Engineering Division, 410 Sackett Point Rd., North Haven, CT 06473.

${ }^{3}$ Catalyst System Engineer, Microlith ${ }^{\circledR}$ Products, 410 Sackett Point Rd., North Haven, CT 06473.

${ }^{4}$ Director, Microlith ${ }^{\circledR}$ Products, 410 Sackett Point Rd., North Haven, CT 06473.

5 Aerospace Engineer, Environmental Control and Life Support Systems Development Branch, Bldg 4755 Room 403-7, NASA MSFC, Huntsville, AL 35812.

${ }^{6}$ Senior Engineer, Environmental Control Systems, Engineering Directorate, Space Systems Department, ECLS System Development Branch/ES62, NASA MSFC, Huntsville, AL 35812. 


$\begin{array}{ll}\text { mol } & =\text { mole } \\ \text { psia } & =\text { pound per square inch absolute } \\ \text { slpm } & =\text { standard liter per minute }\left(21^{\circ} \mathrm{C}, 14.7 \mathrm{psia}\right) \\ W H S V & =\text { weight hourly space velocity } \\ w t \% & =\text { percent by weight }\end{array}$

\section{Introduction}

$\mathrm{T}$ The closed-loop cabin Atmosphere Revitalization System (ARS), which includes the $\mathrm{CO}_{2}$ Removal Assembly (CDRA), Oxygen Generator Assembly (OGA), and $\mathrm{CO}_{2}$ Reduction Assembly (CRA), has become an integral part of NASA mission architectures for future long-duration human space exploration to the Moon and Mars. ${ }^{1,2}$ In the current International Space Station (ISS) and other low orbit missions, the metabolically generated $\mathrm{CO}_{2}$ is removed from the cabin air and vented into space, resulting in a net loss of $\mathrm{O}_{2}$. This requires a continuous resupply of $\mathrm{O}_{2}$ via water electrolysis, and thus highlights the need for large water storage. ${ }^{3}$ For long-duration space missions, the amount of life support consumables (e.g., $\mathrm{O}_{2}$ and $\mathrm{H}_{2} \mathrm{O}$ ) is limited and the resupply option is practically nonexistent, and thus atmosphere resource management and recycle become crucial. To achieve a complete closure of $\mathrm{O}_{2}$ and $\mathrm{H}_{2} \mathrm{O}$, the $\mathrm{CO}_{2}$ produced by metabolic processes is removed from the cabin air by CDRA and is then reacted with $\mathrm{H}_{2}$ from OGA in a Sabatier $\mathrm{CO}_{2}$ methanation reactor (i.e., part of CRA) to produce methane and water. ${ }^{4,5}$ A highly efficient closed-loop ARS will result in a near complete closure of $\mathrm{O}_{2}$, which would significantly reduce the required amount of water resupply, providing cost and logistics savings. Additionally, the use of the Sabatier process as part of the In-Situ Resource Utilization (ISRU) application for on-site production of life support consumables and propellants from Lunar and Martian regolith (i.e., $\mathrm{CO}_{2}$ and $\mathrm{CO}$ from carbothermal reduction of regolith or from the Martian atmosphere) is of interest to NASA. ${ }^{6-8}$

In the Sabatier or $\mathrm{CO}_{2}$ methanation process, $\mathrm{CO}_{2}$ reacts with hydrogen in the presence of catalysts to produce methane and water, as shown in Eq. (1) below:

$$
\mathrm{CO}_{2}+4 \mathrm{H}_{2} \rightarrow \mathrm{CH}_{4}+2 \mathrm{H}_{2} \mathrm{O} \quad \Delta \mathrm{H}^{0}=-165 \mathrm{~kJ} / \mathrm{mol}
$$

Similarly, trace $\mathrm{CO}$ can also catalytically react with hydrogen to produce methane and water as shown in Eq. (2). Additionally, a competing reverse water gas shift (RWGS) reaction, Eq. (3), is typically present. Under certain operating conditions, $\mathrm{CO}_{2}$ reduction via the Bosch reaction may also occur, where $\mathrm{CO}_{2}$ reacts with hydrogen to form carbon and $\mathrm{H}_{2} \mathrm{O}$, as shown in Eq. (4). Both Eqs. (3) and (4) reduce the selectivity towards methane formation. Furthermore, the Bosch process is undesireable in this system since the resulting carbon can deposit on the catalyst surface, thus reducing the catalyst activity and performance as well as increasing the pressure drop.

$$
\begin{gathered}
\mathrm{CO}+3 \mathrm{H}_{2} \rightarrow \mathrm{CH}_{4}+\mathrm{H}_{2} \mathrm{O} \\
\mathrm{CO}_{2}+\mathrm{H}_{2} \rightarrow \mathrm{CO}+\mathrm{H}_{2} \mathrm{O} \\
\mathrm{CO}_{2}+2 \mathrm{H}_{2} \rightarrow \mathrm{C}_{(s)}+2 \mathrm{H}_{2} \mathrm{O}
\end{gathered}
$$

The water produced by the Sabatier process can then be collected via centrifugation, condensation, or an adsorption method and used as is or it can be further electrolyzed using photovoltaic solar energy to form $\mathrm{O}_{2}$ and $\mathrm{H}_{2}$. Hydrogen can be recycled back to the Sabatier reactor for carrying out more $\mathrm{CO}_{2}$ reduction. Methane can be vented overboard, stored and used as a rocket propellant or passed through a pyrolysis reactor to recover $\mathrm{H}_{2}$ for recycle, depending on the applications. For safety reasons, the Sabatier reactor for space applications would be operated at slightly less than ambient pressure in order to prevent leakage of combustible gasses to the atmosphere surrounding the unit.

The Sabatier process is an exothermic reaction and is limited by the thermodynamic equilibrium. Lower operating temperatures, typically around $250-400^{\circ} \mathrm{C}$, are desirable for higher $\mathrm{CO}_{2}$ conversion and higher $\mathrm{CH}_{4}$ selectivity. To date, extensive studies have been performed by others to evaluate and to compare the activity and selectivity of various catalysts, such as $\mathrm{Ni}, \mathrm{Ru}$, and $\mathrm{Rh}$ for the Sabatier reaction. Nickel is the traditional Sabatier catalyst that has been extensively investigated, while ruthenium was reported as the most active catalyst with the highest selectivity toward $\mathrm{CH}_{4}{ }^{9}{ }^{910}$ The Sabatier reaction tests performed in these studies, however, were carried out 
in packed-bed reactors consisting of catalyst pellets. Recently, researchers at Pacific Northwest National Lab (PNNL) have designed and tested catalytic microchannel reactors for the Sabatier process, and have shown improved $\mathrm{CO}_{2}$ conversion due to better heat and mass transfers compared to the traditional packed-bed reactors. ${ }^{7,8}$ Despite the performance improvement demonstrated by the microchannel reactors, the highest obtainable $\mathrm{CO}_{2}$ conversion was still relatively low at high throughputs (i.e., $\left.\geq 30,000 \mathrm{hr}^{-1}\right) \cdot{ }^{6,7}$ Additionally, the $\mathrm{CO}_{2}$ conversion decreased from $70 \%$ to $\sim 62 \%$ during 4 days of operation (i.e., $\sim 100$ hours) and further decreased to $\sim 50 \%$ at the end of the 14-day testing period indicating significant catalyst deactivation. ${ }^{6}$

In this paper, we describe the development of a compact and lightweight Microlith-based Sabatier reactor prototype capable of achieving high $\mathrm{CO}_{2}$ conversion and near complete $\mathrm{CH}_{4}$ selectivity (i.e., $\geq 90 \%$ of the thermodynamic equilibrium values) at high space velocities. The reactor was operated at $30,000-60,000 \mathrm{hr}^{-1}$ gas hourly space velocity (GHSV) and at average operating temperatures of $\leq 400^{\circ} \mathrm{C}$. Additionally, the versatility of the reactor was demonstrated by operating under $\mathrm{H}_{2}$-rich $\left(\mathrm{H}_{2} / \mathrm{CO}_{2}\right.$ ratio of $>4$ ), stoichiometric (ratio of 4), and $\mathrm{CO}_{2}$-rich (ratio of $<4$ ) conditions. The ability to operate the Microlith-based reactor at high space velocities results in a compact and lightweight Sabatier reactor that will reduce size and launch costs. Based on the test results, an approximately $14 \mathrm{ml}$ reactor (excluding the heat exchanger) is sufficient for a 4-crew unit. The current estimate of the required Microlith catalytic substrate is 3.1 grams per crew. These performance metrics would reduce the size and weight of the overall CRA unit to meet NASA's target values for specific mass and specific volume. ${ }^{11}$ Finally, both performance durability for 100 hours and mechanical durability of the Microlith catalytic substrates are discussed. In general, the high surface area per volume of the catalytic Microlith substrates is expected to help with the kinetically-controlled reaction, the short channel length of Microlith substrates is expected to aid the mass transfer controlled reaction, and the metallic support should improve conductive heat transfer to avoid local hot spots and increase durability to withstand mechanical and thermal shocks. ${ }^{12,13}$

\section{Microlith ${ }^{\circledR}$ Catalytic Technology}

The catalyst and reactor described here are based on PCI's patented Microlith technology (trademarked by PCI). ${ }^{14}$ The Microlith substrate consists of a series of ultra-short-channel-length, catalytically coated metal meshes with very small channel diameters (Fig. 1). The mesh-like substrates provide very high heat and mass transfer coefficients, low thermal mass, and extremely high reaction rates. The use of this kind of reactor, where the reacting stream is passed through the catalyst at extremely high space velocity, is generically termed a short contact time (SCT) approach. Whereas in a conventional honeycomb monolith, a fully developed boundary layer is present over a considerable length of the device, the ultra-short-channel-length Microlith substrate minimizes boundary layer buildup, resulting in remarkably high heat and mass transfer coefficients compared to other substrates (e.g., monoliths, foams, and pellets). In catalytic reactors involving exothermic reactions, such as the Sabatier process, enhanced heat transfer properties are necessary to eliminate local hot spots and temperature excursions at the catalyst surface, and to prevent catalyst deactivation due to metal sintering. The Microlith substrate also provides about three times higher geometric surface area over conventional monolith reactors with equivalent volume and open frontal area (i.e., low pressure drop).
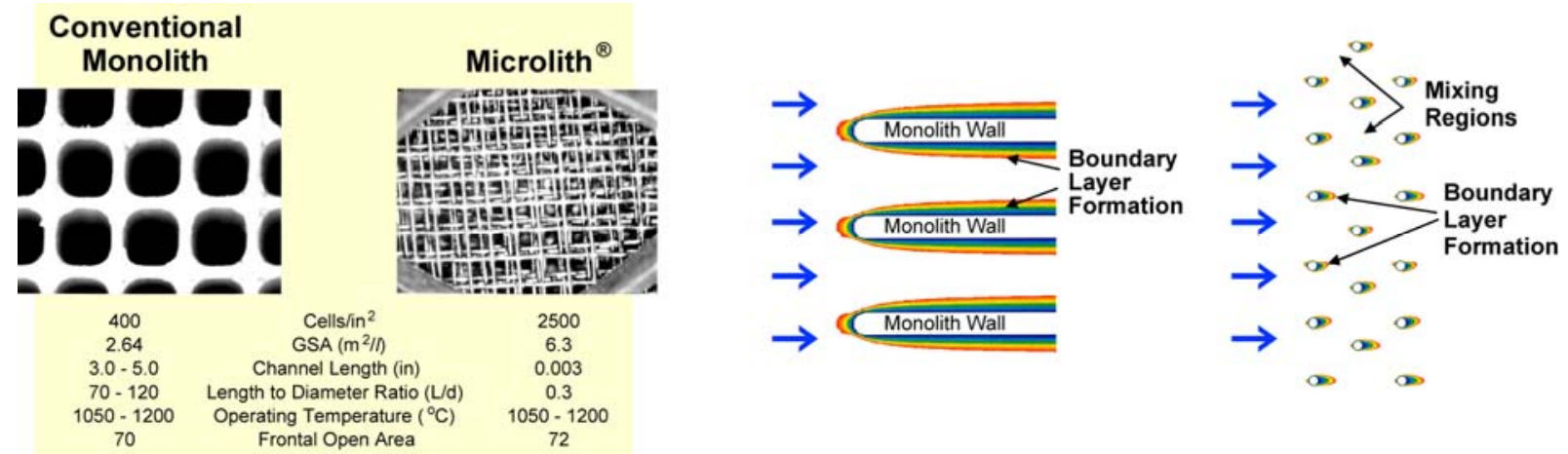

Figure 1. Physical characteristics of conventional, long honeycomb monolith and Microlith substrates, and CFD analysis of boundary layer formation for a conventional monolith and three Microlith screens.

The heat and mass transfer coefficients depend on the boundary layer thickness. For a conventional long channel honeycomb monolith, a fully developed boundary layer is present over a considerable length of the catalytic surface, thus limiting the rate of reactant transport to the surface of active sites. This is avoided when short channel length 
catalytic screens are used. A Computational Fluid Dynamics (CFD) analysis (Fig. 1) illustrates the difference in boundary layer formation between a monolith and Microlith screens. Finally, PCI's proprietary catalyst coating formulations and application methods, with high surface area washcoats, allow for very low catalyst usage with rigorously demonstrated long-term mechanical, thermal, and performance durability.

Another advantage of using a Microlith substrate is that it requires neither a completely premixed, completely vaporized, nor completely uniform mixture for stable operation. The high mass transfer rate of the Microlith substrate provides sufficient mixing to remove small-scale inhomogeneities in the reactor feed, but large scale variations still need to be removed upstream of the reactor. Therefore, a simple reactant mixture preparation strategy, using a standard static or quartz mixer, can be employed without risk of damaging the catalytic Microlith substrates. PCI has had considerable experience in providing a highly uniform mixture to the reactor and has identified simple premixing techniques with the design elements necessary for good reactor stability. The results demonstrated by the Microlith-based reactors in water gas shift reaction, partial oxidation of methane, oxidative steam reforming of methanol, and highly exothermic $\mathrm{H}_{2} \mathrm{O}_{2}$ decomposition offer its potential for effective catalytic $\mathrm{CO}_{2}$ reduction via the Sabatier process.

The use of catalyst substrates with high heat and mass transfer rates, high surface area, and low pressure drop has a significant impact on reactor performance and size. Current catalytic reactors are generally based on substrates such as pellets, monoliths, foams or microchannels. Work on short contact time substrates has been reported by groups at National Labs, universities, and commercial organizations. Notable among them is Professor Lanny Schmidt at the University of Minnesota. ${ }^{15,16}$ However, PCI's Microlith short contact time substrate has shown several benefits over other such substrates on the basis of recent results and developments. The effectiveness of the Microlith technology and long-term durability of PCI's proprietary catalyst coatings have been systematically demonstrated in different applications. These include exhaust aftertreatment, ${ }^{17}$ trace contaminant control, ${ }^{18,19}$ catalytic combustion, ${ }^{20}$ partial oxidation of methane, ${ }^{12,21}$ liquid fuel reforming, ${ }^{13} \mathrm{CO}$ preferential oxidation, and water gas shift reactors. ${ }^{22}$ A scanning electron microscopy (SEM) micrograph of the coated Microlith substrate is shown in Fig. 2. SEM analysis indicates uniform catalyst coatings on the substrate with complete coverage.

\section{Results and Discussion}

\section{A. Design and Fabrication of Sabatier Reactor}

Designing a suitable reactor for the exothermic Sabatier reaction is a key challenge. As mentioned before, a low operating temperature is preferred for the Sabatier reaction in order to achieve high reactant conversions and $\mathrm{CH}_{4}$ selectivity due to the thermodynamic limitations at higher operating temperatures. However, the reaction is severely kinetically limited at low operating temperatures, which will result in reaction quenching due to slow rates of reaction. To remedy this, typical Sabatier reactors are operated with long residence times (i.e., low GHSV) resulting in bulky systems. Additionally, commonly used pellet catalyst beds have low heat transfer coefficients which create another challenge when trying to achieve uniform reactor operating temperatures. Local hot spots are typically encountered in pellet catalyst beds which lead to catalyst deactivation due to metal sintering. TDA Research has developed a prototype consisting of a $\mathrm{CO}_{2}$ removal bed and a two-bed Sabatier reactor for $\mathrm{CO}_{2}$ methanation that attempts to mitigate this problem. ${ }^{23,24}$ Having two reactor modules, however, negatively impacts the weight and volume of the system.

PCI recently identified and implemented an approach for reactor operation at thermodynamically favored conditions to achieve high $\mathrm{CO}_{2}$ conversion and high $\mathrm{CH}_{4}$ selectivity at high space velocities without catalyst degradation. This novel approach was made possible by the use of high-heat-transfer and high-surface-area Microlith catalytic substrates, allowing catalyst operation at conditions favorable for thermodynamic equilibrium of $\mathrm{CO}_{2}$ methanation. 
The Sabatier reactor prototype consisted of an approx. 8" long, 1" diameter stainless steel tube which contained approximately $12 \mathrm{ml}\left(\sim 0.73 \mathrm{in}^{3}\right)$ of catalyst bed. A photo of the reactor is shown in Fig. 3. The catalysts, which can be either catalytically coated-Microlith substrates or catalyst pellets, were inserted into the stainless steel tube. The reactor was equipped with multiple thermocouples and two sample ports. The thermocouples were used to monitor catalyst bed temperatures at several radial and axial locations, reactor wall temperatures, and inlet and outlet gas temperatures. Two sample ports were used to monitor the inlet feed and outlet product compositions. A pre-mixing region consisting of quartz beads was inserted upstream of the catalyst bed to enhance the reactants mixing (i.e., pure $\mathrm{H}_{2}$ and pure $\mathrm{CO}_{2}$ with known $\mathrm{N}_{2}$ as internal standard). During the performance testing, the average catalyst bed temperature was maintained at the desired values. The catalyst bed volume was only $\sim 12 \mathrm{ml}$, and was sized to operate with GHSVs in the range of 30,000 to $60,000 \mathrm{hr}^{-1}$. This resulted in a total gas flow rate that can represent a system for $\sim 3.5-7$ crew members.

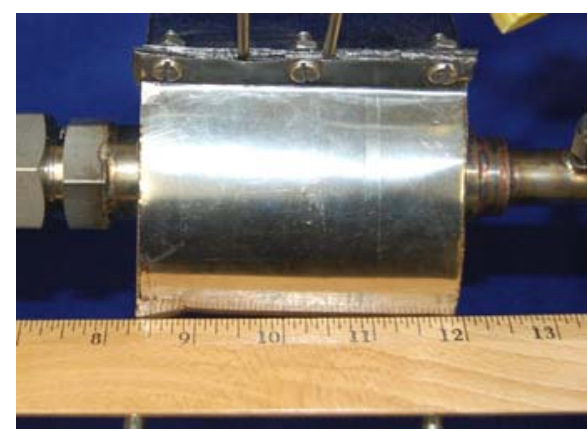

Figure 3. Photo of the Sabatier reactor prototype developed at PCI.

\section{B. Sabatier Reactor Performance Testing}

A test matrix was developed and finalized in order to evaluate the catalyst performance and to optimize the operating conditions for the Microlithbased Sabatier reactor. Table 1 lists the test plan implemented to develop the performance maps for both Ru-coated and Rh-coated Microlith substrates. In this study, inlet temperature, $\mathrm{H}_{2} / \mathrm{CO}_{2}$ ratio, GHSV, and operating pressure were varied for each catalyst. $\mathrm{CO}_{2}$ conversion and $\mathrm{CH}_{4}$ selectivity were calculated by measuring the product gas composition at these operating conditions. The performance of the two metal catalysts was then compared, and a pellet version of the $\mathrm{Ru}$ catalyst was acquired and tested to compare the performance against the Microlith-based catalyst. From these tests, the potential benefits of the Microlith substrate were validated, including short contact time kinetics, high heat transfer, and high surface area of catalyst active sites, to achieve a highly efficient, compact, and durable Sabatier reactor.

In this study, the Sabatier reactor testing was performed using: (i) Ru catalyst coated on Microlith substrate; (ii) $\mathrm{Rh}$ catalyst coated on Microlith substrate; and (iii) Pellet catalyst version of ruthenium (Sigma Aldrich, product \# 206199). Performance maps for these catalysts were developed as a function of $\mathrm{H}_{2} / \mathrm{CO}_{2}$ ratio, operating temperature, space velocity, and pressure according to the test matrix. These catalysts were first reduced under the optimum reduction conditions prior to performance testing. $\mathrm{CO}_{2}$ conversion and $\mathrm{CH}_{4}$ selectivity were calculated at each operating condition by measuring the product composition using gas chromatograph with $\mathrm{N}_{2}$ as the internal standard. These three catalysts were compared based on both GHSV and weight hourly space velocity (WHSV) due to the potential difference in catalyst metal loading of the three substrates within the same reactor volume.

The performance of Ru- and Rh-coated Microlith catalytic substrates were examined by evaluating the $\mathrm{CO}_{2}$ conversion and $\mathrm{CH}_{4}$ selectivity at GHSVs from 30,000 to $60,000 \mathrm{hr}^{-1}, \mathrm{H}_{2} / \mathrm{CO}_{2}$ ratios from 3.5 to 5.5 , reactant partial pressures from 8.3 to $13.2 \mathrm{psia}$, and temperatures from 250 to $450^{\circ} \mathrm{C}$. Figure 4 shows the test results from both Ruand Rh-Microlith catalysts at 30,000 $\mathrm{hr}^{-1}$ and different $\mathrm{H}_{2} / \mathrm{CO}_{2}$ ratios. On average, the $\mathrm{CO}_{2}$ conversion was found to approach $90-95 \%$ of the isothermal equilibrium conversion at the optimum operating conditions. $\mathrm{CH}_{4}$ selectivity was found to be within $95-100 \%$ of the isothermal equilibrium selectivity for both Microlith catalytic substrates regardless of the operating conditions. Rh-Microlith catalyst was found to be slightly more active than the $\mathrm{Ru}$-Microlith catalyst when compared on a GHSV basis, due to its higher metal loading, which resulted in $\mathrm{CO}_{2}$ conversions of $\sim 7-8 \%$ higher than those obtained for the Ru-Microlith (Fig. 4). When compared on a WHSV basis, which accounts for the difference in metal loading, however, the performance was found to be nearly identical. 
Catalyst Comparison at GHSV of $30 \mathrm{~K} \mathrm{hr}^{-1}$ and $\mathrm{H}_{2} / \mathrm{CO}_{2}$ of $\sim 3.5$ : Temperature Sweep

$\mathrm{CO}_{2}$ Conversion (\%)

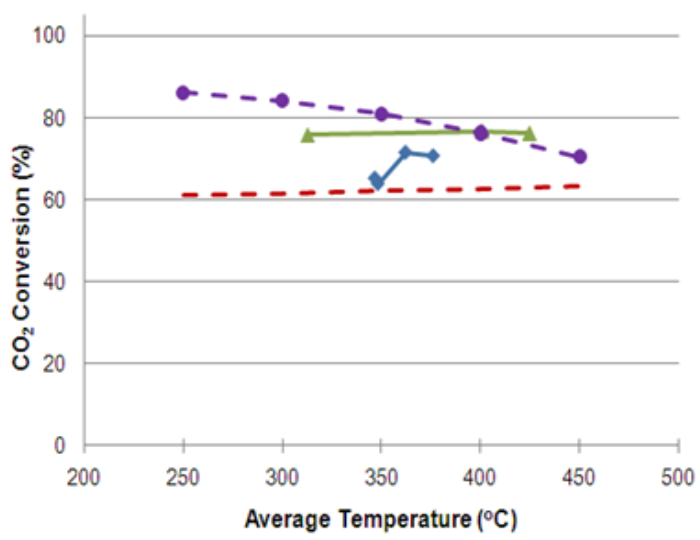

$\mathrm{CH}_{4}$ Selectivity (\%)

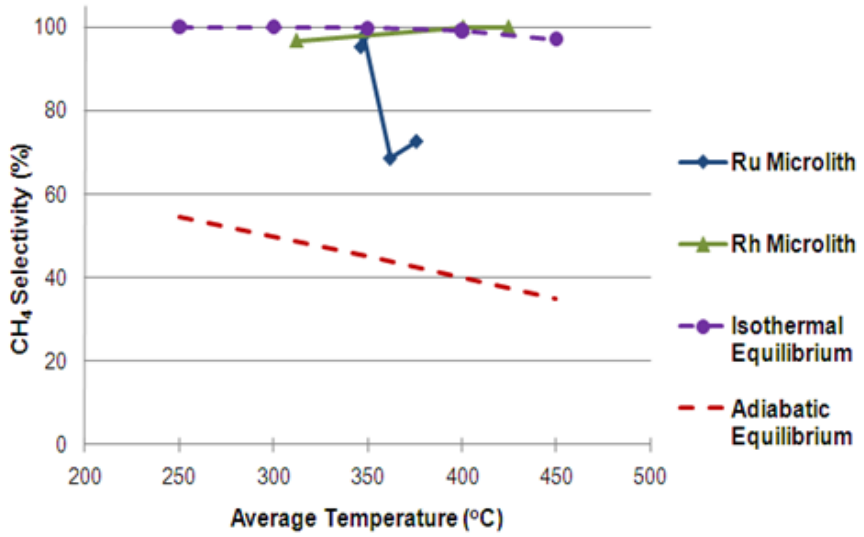

Catalyst Comparison at GHSV of $30 \mathrm{~K} \mathrm{hr}^{-1}$ and $\mathrm{H}_{2} / \mathrm{CO}_{2}$ of $\sim 4$ : Temperature Sweep

$\mathrm{CO}_{2}$ Conversion (\%)

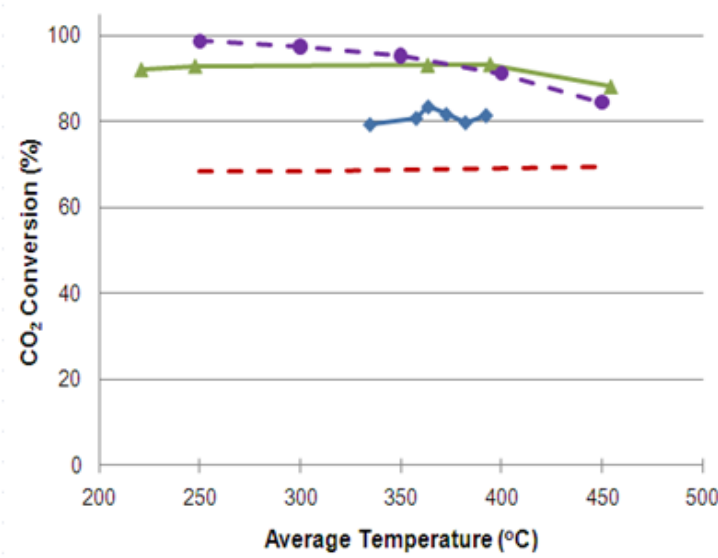

$\mathrm{CH}_{4}$ Selectivity (\%)

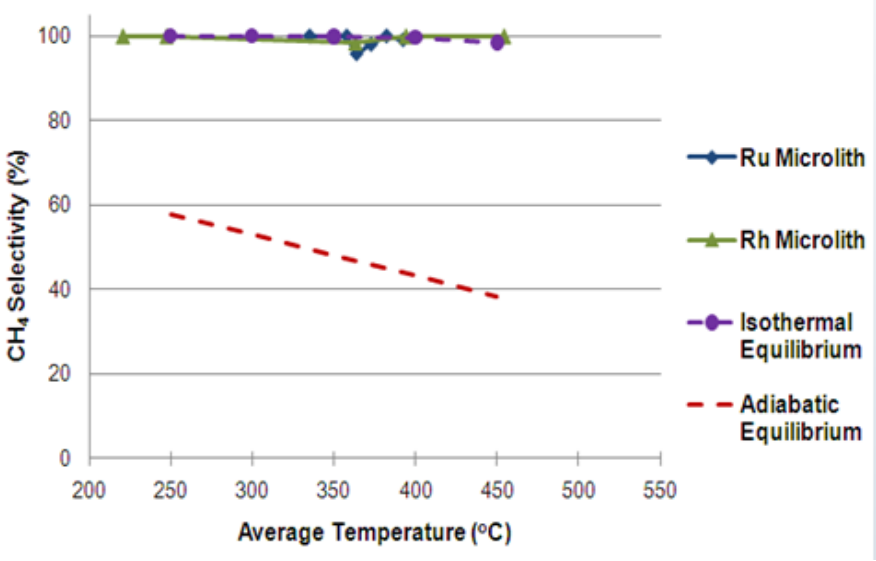

Catalyst Comparison at GHSV of $30 \mathrm{~K} \mathrm{hr}^{-1}$ and $\mathrm{H}_{2} / \mathrm{CO}_{2}$ of $\sim 5.5$ : Temperature Sweep

$\mathrm{CO}_{2}$ Conversion (\%)

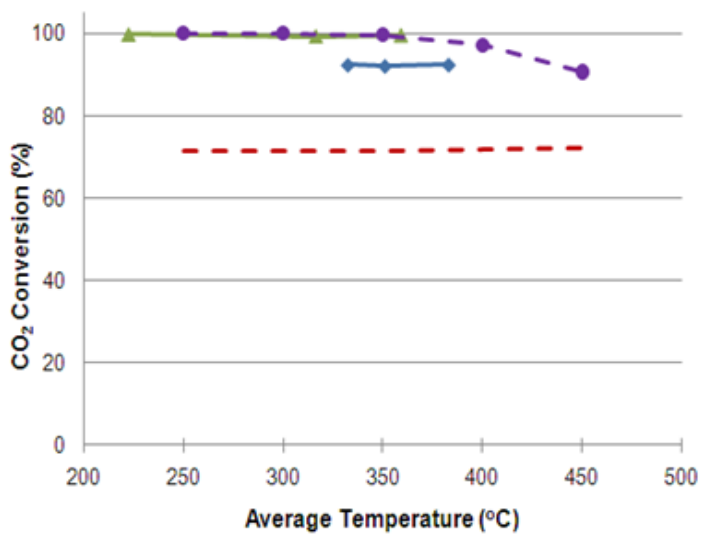

$\mathrm{CH}_{4}$ Selectivity (\%)

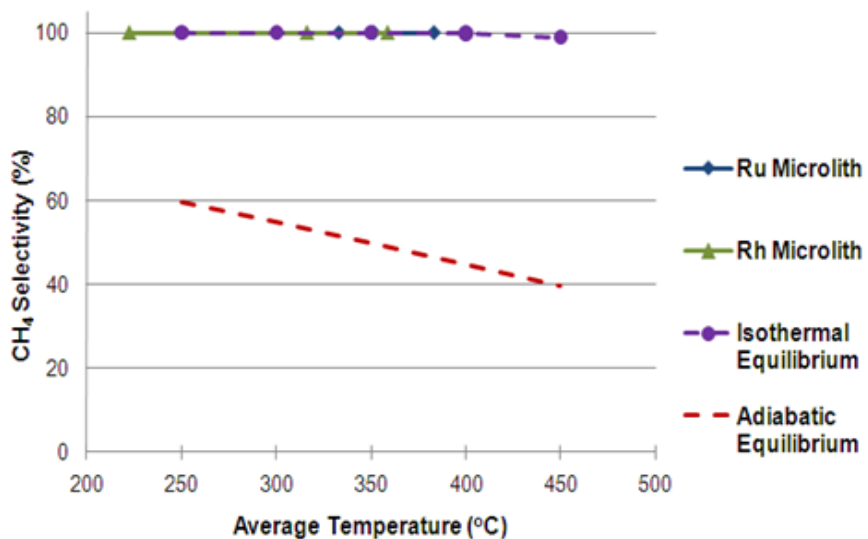

Figure 4. Comparison between Ru- and Rh-Microlith catalysts at $30,000 \mathrm{hr}^{-1}$ and different $\mathrm{H}_{2} / \mathrm{CO}_{2}$.

6

American Institute of Aeronautics and Astronautics 
Both of the catalysts followed the same general trends in regard to GHSV, $\mathrm{H}_{2} / \mathrm{CO}_{2}$ ratio, partial pressure, and temperature. $\mathrm{CO}_{2}$ conversion improved at lower space velocities due to longer residence times within the reactor. $\mathrm{CO}_{2}$ conversion also improved with higher $\mathrm{H}_{2} / \mathrm{CO}_{2}$ ratios due to the hydrogen rich feed. Operating pressure was found to have minimal effect on the reactor performance, which suggests that the reactor can be operated under vacuum conditions without losses in performance. $\mathrm{CO}_{2}$ conversion reached a maximum at around $350^{\circ} \mathrm{C}$ for the Microlith catalytic substrates. The improved heat and mass transfer characteristics inherent in the Microlith substrate enabled cooler and more uniform catalyst temperatures along with higher $\mathrm{CO}_{2}$ conversions when compared to stateof-the-art pellet catalysts and microchannel reactors. The ability to operate at a much higher GHSV while still exceeding the $\mathrm{CO}_{2}$ conversion obtained from pellet catalysts, also gives Microlith-based Sabatier reactors an added benefit of a smaller reactor size.

Table 2 lists the optimum $\mathrm{CO}_{2}$ conversions obtained from the Ru-Microlith, Rh-Microlith, and $\mathrm{Ru}$ pellet catalyst testing at different $\mathrm{H}_{2} / \mathrm{CO}_{2}$ ratios, at $\sim 30,000 \mathrm{hr}^{-1}$ GHSV $\left(\sim 23,500 \mathrm{hr}^{-1}\right.$ for Ru pellets to maintain the same WHSV with Ru-Microlith catalyst), and at a reactant pressure of 13.2 psia. The value obtained from literature for PNNL's microchannel reactor operating at $\sim 30,000 \mathrm{hr}^{-1}$ is also listed for comparison. ${ }^{7}$ Test results indicated that short-contact-time kinetics and high-surfacearea benefits of the Microlith substrates assisted the Sabatier reaction to achieve high reactant conversions and near $100 \% \mathrm{CH}_{4}$ selectivity at high throughputs (i.e., $30,000-60,000 \mathrm{hr}^{-1}$ vs. $18,000-$ $45,000 \mathrm{hr}^{-1}$ for PNNL's microchannel reactor vs. $1,800 \mathrm{hr}^{-1}$ for state-of-the art pellet-based reactors).

Table 2. Optimum $\mathrm{CO}_{2}$ conversions for Ru-Microlith, Rh-Microlith, and Ru pellet catalysts at different $\mathrm{H}_{2} / \mathrm{CO}_{2}$ ratios and $30 \mathrm{~K} \mathrm{hr}^{-1} \mathrm{GHSV}\left(23.5 \mathrm{~K} \mathrm{hr}^{-1}\right.$ for Ru pellets to maintain the same WHSV with Ru-Microlith catalyst).

\begin{tabular}{|c|c|c|}
\hline \multirow{2}{*}{ Catalyst } & $\begin{array}{c}\text { Approx. } \\
\mathbf{H}_{\mathbf{2}} / \mathbf{C O}_{2} \text { ratio }\end{array}$ & $\begin{array}{c}\text { Max } \mathbf{C O}_{2} \\
\text { conversion (\%) }\end{array}$ \\
\hline \multirow{3}{*}{ Ru-Microlith } & 3.5 & 71 \\
\cline { 2 - 3 } & 4 & 83.5 \\
\cline { 2 - 3 } & 5.5 & 93 \\
\hline \multirow{2}{*}{ Rh-Microlith } & 3.5 & 77 \\
\cline { 2 - 3 } & 4 & 92 \\
\hline \multirow{2}{*}{$\begin{array}{c}\text { Commercially } \\
\text { available Ru pellets }\end{array}$} & 5.5 & 99.8 \\
\cline { 2 - 3 } & 3.5 & 66 \\
\hline $\begin{array}{c}\text { PNNL (single } \\
\text { microchannel; Ru) }\end{array}$ & 4 & 76 \\
\hline
\end{tabular}

\section{Performance Durability of Microlith-based Sabatier Reactor}

Durability of the catalyst-coated Microlith substrates was examined by continuously running each Rh-based and Ru-based catalyst for a period of 100 hours while subjecting them to 5 startup/shutdown sequences over the course of the test. $\mathrm{CO}_{2}$ conversion was monitored throughout the test to determine how much, if any, performance degradation had occurred. Both catalysts were tested at a GHSV of 30,000 $\mathrm{hr}^{-1}, \mathrm{a} \mathrm{H}_{2} / \mathrm{CO}_{2}$ ratio of $\sim 3.5$ per NASA request (i.e., $\mathrm{CO}_{2}$-rich condition for spaceflight applications), and a reactant partial pressure of $13.2 \mathrm{psia}$. This operating condition was chosen to represent a realistic condition in spacecraft and ISS applications. The operating temperature was chosen to achieve the maximum $\mathrm{CO}_{2}$ conversion at this condition (i.e., at a $\mathrm{H}_{2} / \mathrm{CO}_{2}$ of 3.5), which were $71 \%$ for $\mathrm{Ru}-$ Microlith and $77 \%$ for $\mathrm{Rh}-$ Microlith catalysts (vs. isothermal equilibrium $\mathrm{CO}_{2}$ conversion of 77 $79 \%$ at a $\mathrm{H}_{2} / \mathrm{CO}_{2}$ ratio of 3.5 and at $350-375^{\circ} \mathrm{C}$ ). No performance degradation was observed for either catalyst over the course of the 100 hours of operation with 5 starts/stops as shown in Fig. 5. The lack of catalyst degradation suggested that the high heat transfer rate of the Microlith catalytic substrates permits uniform temperature distribution and avoids local hot spots that can cause metal sintering and catalyst deactivation.

Due to the fact that the cooling system was manually controlled, it could not be adjusted overnight in response to changes in the ambient temperature or other uncontrolled variables that affected the temperature within the reactor. This often led to a slight cooling of the Sabatier reactor and a corresponding slight decrease in the performance overnight. This behavior was not related to the catalyst degradation because performance always returned upon either readjusting the cooling system to maintain the reactor at the optimum operating temperature or restarting the Sabatier reactor. To overcome this challenge in the field, a control system would need to be developed to maintain a constant temperature profile within the reactor. An appropriate control algorithm will be developed and implemented in future development efforts for the long-term, unattended performance testing over 1000 hours. Despite these challenges, no catalyst performance degradation was observed for either of the Microlith catalyst substrates while operating the reactor at a high throughput (i.e., GHSV of 30,000 $\mathrm{hr}^{-1}$ ). This is an additional potential benefit over pellet catalysts since typical pellet catalysts often suffer from metal sintering due to local hot spots (in the exothermic reactors), which degrades the catalyst and causes the active region to move to different areas of the bed over time. To account for this inevitable degradation, pellet reactors must be oversized to provide longer life 
spans without replacing the catalyst. If Microlith catalytic substrates are able to overcome this problem, as is suggested by the durability test data, it will be possible to use smaller reactors and still run for extended periods of time without performance degradation or catalyst replacement.

\section{Mechanical Vibration Testing}

An in-house mechanical vibration test was performed on Ru-Microlith, $\mathrm{Rh}$ Microlith, and commercially available $\mathrm{Ru}$ pellet catalysts to further evaluate the adhesion and durability of catalyst coating on Microlith substrates and to compare it with the catalyst pellets. The test consisted of a $12 " \times 12$ " vibrating aluminum plate supported on vibration isolation mounts and excited by an industrial-style pneumatic vibrator (recirculating ball style) mounted either in the center or on the edge of the plate to simulate the launch vibration loads. An example of the vibration test setup is shown in Fig. 6. Assembled catalyst beds of Rh-Microlith and Ru-Microlith were placed in a pre-weighed, zip-closed plastic bag to contain the loosened catalyst. The $\mathrm{Ru}$ catalyst pellets were placed inside a small, capped stainless steel tube container. Each catalyst was then attached to the plate and was vibrated for a total of $\sim 80$ minutes. The amount of catalyst lost was collected and weighed. In this vibration test, the peak force averaged $\sim 50 \mathrm{gs}$ and the primary frequency was $250 \mathrm{~Hz}$. The vibration test results indicated that the Microlith-based catalyst coating lost was $<\sim 0.2$ wt. $\%$, lower than that observed from the Ru pellets (Fig. 7). Here, the coating weight lost for the Microlith catalyst substrates was defined as

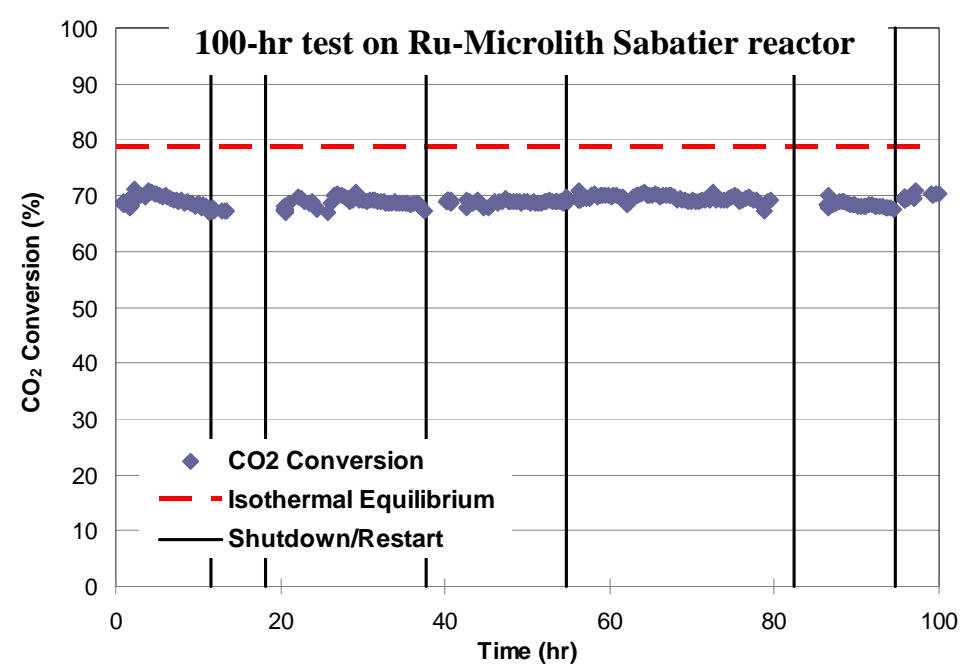

a)

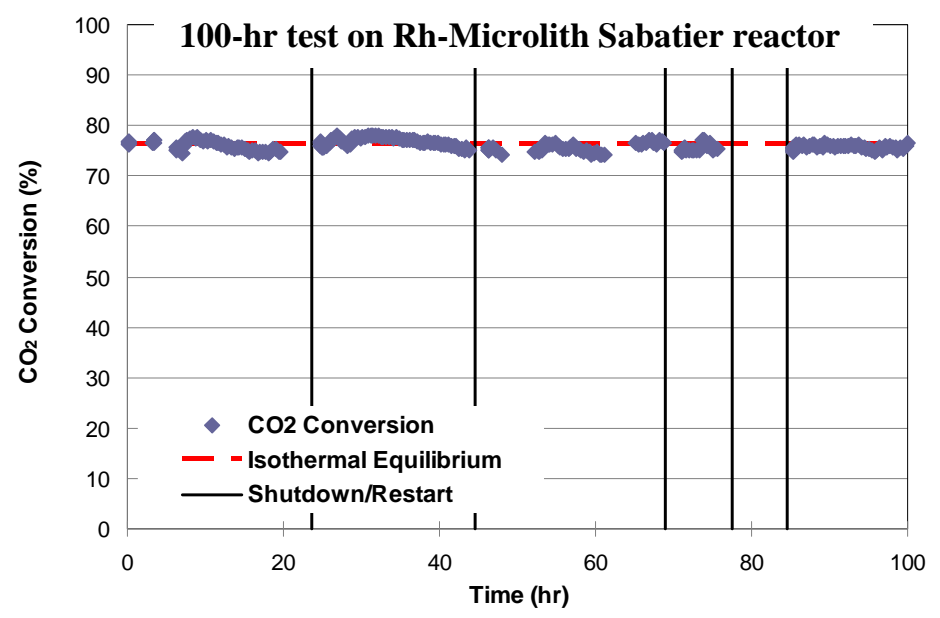

b)

Figure 5. $\mathrm{CO}_{2}$ conversion as a function of time from the 100hour durability testing of: a) Ru-Microlith catalyst and b) RhMicrolith catalyst performed at a GHSV of $30,000 \mathrm{hr}^{-1}, \mathrm{H}_{2} / \mathrm{CO}_{2}$ ratio of $\sim 3.5$, and operating pressure of $13.2 \mathrm{psia}$. The isothermal equilibrium $\mathrm{CO}_{2}$ conversion at $\sim 77-79 \%$ (for $350-375^{\circ} \mathrm{C}$ temperature) is included for comparison.

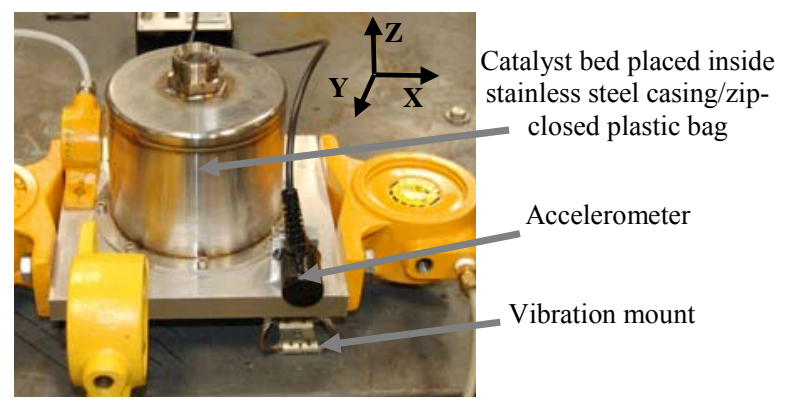

Figure 6. An example of the vibration test setup to evaluate the adhesion and mechanical durability of the Microlith-based catalysts against simulated launch vibration loads.

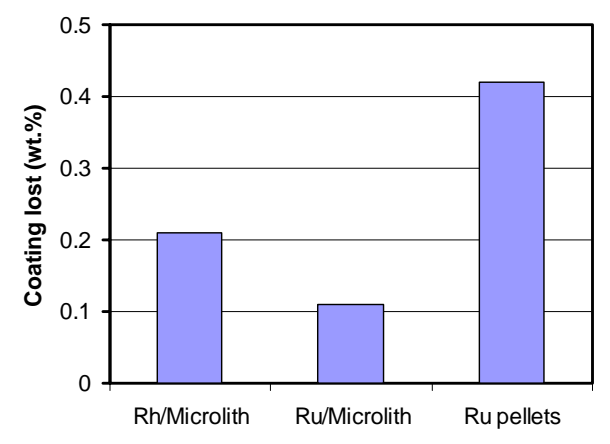

Figure 7. Catalyst lost (i.e., “fines" generated) from the mechanical vibration testing.

8

American Institute of Aeronautics and Astronautics 
the ratio of the amount of "fines" generated to the amount of the catalyst and washcoat only (without taking into account the weight of the Microlith substrate which would not contribute to any losses). On the other hand, the coating weight lost for the catalyst pellets was defined as the ratio of the amount of "fines" generated to the total amount of the pellets since the support material will contribute to losses.

\section{Conclusion}

This paper demonstrates the benefit of the Microlith catalytic substrates for efficient Sabatier reaction. The properties of short contact time kinetics, high heat transfer, and high surface area of catalyst active sites enable the design of a highly efficient, compact, and durable Sabatier reactor. A proof-of-concept Microlith-based Sabatier reactor capable of producing high $\mathrm{CO}_{2}$ conversion and near $100 \% \mathrm{CH}_{4}$ selectivity (i.e., $\geq 90 \%$ of the thermodynamic equilibrium values) at high space velocities and low operating temperatures was developed and demonstrated. The reactor was operated at GHSVs of 30,000-60,000 $\mathrm{hr}^{-1}$. Additionally, the versatility of the Microlith-based reactor was demonstrated by operating it under $\mathrm{H}_{2}$-rich $\left(\mathrm{H}_{2} / \mathrm{CO}_{2}\right.$ ratio of $>4$ ), stoichiometric (ratio of 4), and $\mathrm{CO}_{2}$-rich (ratio of $<4$ ) conditions without affecting its performance.

The ability to operate the Microlith-based reactor at high space velocities results in a compact and lightweight Sabatier reactor that will reduce size and launch costs. Based on the test results, an approximately $14 \mathrm{ml}$ reactor is sufficient for a 4-crew unit, capable of achieving high reactant conversions and high $\mathrm{CH}_{4}$ selectivity. Additionally, the current estimate of the required Microlith catalytic substrate is only 3.1 grams per crew. Finally, both performance durability and mechanical durability of the Microlith catalytic substrates were demonstrated. The performance durability testing for 100 hours on each rhodium- and ruthenium-Microlith catalytic substrate was completed without any performance degradation. The mechanical durability test was performed using an in-house vibration plate at an average peak force of $\sim 50 \mathrm{gs}$ and a primary frequency of $\sim 250 \mathrm{~Hz}$. The resulting "fines" generation was $<\sim 0.2 \mathrm{wt} . \%$, which was lower than the "fines" generation observed from the commercially available $\mathrm{Ru}$ pellets. Thus, in addition to a reduced weight, the implementation of the Microlith-based Sabatier reactor has potential to increase the catalyst durability and to reduce the issues with "fines" generation in the space shuttle application.

\section{Acknowledgments}

This work was supported by the National Aeronautics and Space Administration (NASA) under Contract NNX10CF25P. Any opinions, findings, and conclusions or recommendations expressed in this paper are those of the authors and do not necessarily reflect the views of NASA. The authors are also grateful to the technical and engineering support groups at PCI and NASA MSFC.

\section{References}

${ }^{1}$ Sanders, G. B., Peters, T. A., Wegeng, R. S., TeGrotenius, W. E., Rassat, S. D., Brooks, K. P., and Stenkamp, S., "Report on Development of Micro Chemical/Thermal Systems for Mars ISRU-Based Missions," AIAA Report, AIAA 2001-0939, 2000.

${ }^{2}$ Chamitoff, G., James, G., Baker, D., and Dershowitz, A., "Martian resource locations: Identification and optimization," Acta Astronautica, 56, 756 (2005).

${ }^{3}$ Jeng, F. F., Lewis, J. F., Graf, J. C., and LaFuse, S., "CO${ }_{2}$ Compressor Requirements for Integration of Space Station Carbon Dioxide Removal and Reduction Assemblies," 1999-01-2195, SAE, $29^{\text {th }}$ International Conference on Environmental Systems, Denver, Colorado, 1999.

${ }^{4}$ Murdoch, K., Perry, J., and Smith, F., "Sabatier Engineering Development Unit," 2003-01-2496, SAE, 33 ${ }^{\text {rd }}$ International Conference on Environmental Systems, Vancouver, Canada, 2003.

${ }^{5}$ Knox, J. C., Campbell, M., Murdoch, K., Miller, L. A., and Jeng, F., "Integrated Test and Evaluation of a 4-Bed Molecular Sieve (4BMS) Carbon Dioxide removal System (CDRA), Mechanical Compressor Engineering Development Unit (EDU), and Sabatier Engineering Development Unit (EDU)," 2005-01-2864, SAE, 35 ${ }^{\text {th }}$ International Conference on Environmental Systems, Rome, Italy, 2005.

${ }^{6}$ Holladay, J. D., Brooks, K. P., Wegeng, R., Hu, J., Sanders, J., and Baird, S., "Microreactor development for Martian in situ propellant production," Catalysis Today, 120, 35 (2007).

${ }^{7} \mathrm{Hu}$, J., Brooks, K. P., Holladay, J. D., Howe, D. T., and Simon, T. M., "Catalyst development for microchannel reactors for martian in situ propellant production," Catalysis Today, 125, 103 (2007).

${ }^{8}$ Brooks, K. P., Hu, J., Zhu, H., and Kee, R. J., "Methanation of carbon dioxide by hydrogen reduction using the Sabatier process in microchannel reactors," Chemical Engineering Science, 62, 1161 (2007).

${ }^{9}$ Du, G., Lim, S., Yang, Y., Wang, C., Pfefferle, L., and Haller, G. L., "Methanation of carbon dioxide on Ni-incorporated MCM-41 catalysts: The influence of catalyst pretreatment and study of steady-state reaction," Journal of Catalysis, 249,370 (2007). 
${ }^{10}$ Weatherbee G.D. and C.H. Bartholomew, J. Catal., "Hydrogenation of CO2 on Group VIII Metals, IV. Specific Activities and Selectivities of Silica-Supported Co, Fe, and Ru," 87, 352 (1984).

${ }^{11}$ Perry, J. L., Bagdigian, R. M., and Carrasquillo, R. L., "Trade Spaces in Crewed Spacecraft Atmosphere Revitalization System Development," AIAA Report, AIAA 2010-6061, 40 ${ }^{\text {th }}$ International Conference on Environmental Systems, Barcelona, Spain, 2010.

${ }^{12}$ Lyubovsky, M., Karim, H., Menacherry, P., Boorse, S., LaPierre, R., Pfefferle, W. C., and Roychoudhury, S., "Complete and partial catalytic oxidation of methane over substrates with enhanced transport properties," Catalysis Today, 83, 183 (2003).

${ }^{13}$ Roychoudhury, S., Castaldi, M., Lyubovsky, M., LaPierre, R., and Ahmed, S., "Microlith catalytic reactors for reforming iso-octane-based fuels into hydrogen," Journal of Power Sources, 152, 75 (2005).

${ }^{14}$ Pfefferle, W. C., "Microlith Catalytic Reaction System," U.S. Patent No. 5,051,241. Sept. 24, 1991.

${ }^{15}$ Bitsch-Larsen, A., Degenstein, N. J., and Schmidt, L. D., "Effect of sulfur in catalytic partial oxidation of methane over RhCe coated foam monoliths," Applied Catalysis B: Environmental, 78, 364 (2008).

${ }^{16}$ O'Connor, R. P., Klein, E. J., Henning, D., and Schmidt, L. D., "Tuning millisecond chemical reactors for the catalytic partial oxidation of cyclohexane," Applied Catalysis A: General, 238, 29 (2003).

${ }^{17}$ Bianchi, J. F., Gonzales, F., Muench, G., Pfefferle, W. C., and Roychoudhury, S., "Development and Performance of Microlith Light-off Preconverters for LEV/ULEV," 971023, SAE, $27^{\text {th }}$ International Conference on Environmental Systems, Lake Tahoe, Nevada, 1997.

${ }^{18}$ Carter, R. N., Bianchi, J. F., Pfefferle, W. C., Roychoudhury, S., and Perry, J. L., "Unique Metal Monolith Catalytic Reactor for Destruction of Airborne Trace Contaminants," 972432, SAE, 27 $7^{\text {th }}$ International Conference on Environmental Systems, Lake Tahoe, Nevada, 1997.

${ }^{19}$ Perry, J. L., Carter, R. N., and Roychoudhury, S., "Demonstration of an Ultra-Short Channel Metal Monolith Catalytic Reactor for Trace Contaminant Control Applications," 1999-01-2112, SAE, $29^{\text {th }}$ International Conference on Environmental Systems, Denver, Colorado, 1999.

${ }^{20}$ Kraemer, G., Strickland, T., Pfefferle, W. C., and Ritter, J., “A Compact Catalytic Combustor System for Small Turbogenerators," Proceedings of the International Conference on Joint Power Generation, ASME (1997).

${ }^{21}$ Lyubovsky, M., Roychoudhury, S., and LaPierre, R., "Catalytic partial "oxidation of methane to syngas" at elevated pressures," Catalysis Letters, 99, 113 (2005).

${ }^{22}$ Castaldi, M. J., LaPierre, R., Lyubovsky, M., Pfefferle, W., and Roychoudhury, S., "Effect of water on performance and sizing of fuel-processing reactors," Catalysis Today, 99, 339 (2005).

${ }^{23}$ Alptekin, G., Copeland, R., DeVoss, S., Lind, J., and Smith, F., "An Advanced $\mathrm{CO}_{2}$ Removal and Reduction System," 2004-01-2445, SAE, $34^{\text {th }}$ International Conference on Environmental Systems, Orlando, Florida, 2004.

${ }^{24}$ Alptekin, G., Hitch, B., Dubovik, M., Lind, J., and Smith, F., "Prototype Demonstration of the Advanced $\mathrm{CO}_{2} \mathrm{Removal}_{\text {and }}$ Reduction System," 2005-01-2862, SAE, 35 ${ }^{\text {th }}$ International Conference on Environmental Systems, Rome, Italy, 2005. 